Gut, 1980, 22, 199-202

\title{
In vitro diagnosis of cow's milk protein sensitive enteropathy by organ culture method
}

\author{
N IYNGKARAN*, M YADAV, S BALABASKARAN, AND E SUMITHRAN \\ From the Departments of Paediatrics, Biochemistry, and Pathology, Faculty of Medicine, \\ and the Department of Genetics and Cellular Biology, School of Biological Sciences, \\ University of Malaya, Kuala Lumpur, Malaysia
}

SUMMARY The criteria that are used at present to diagnose cow's milk protein sensitive enteropathy (CMPSE) are based on an in vivo milk challenge which can be hazardous and life threatening. We have used an organ culture model to determine the usefulness of this technique in establishing the diagnosis of CMPSE on the basis of a single biopsy with in vitro milk challenge. Fourteen infants with diarrhoea clinically suspected to have CMPSE were studied prospectively. On the basis of milk challenge studies seven infants had CMPSE. They had clinical reaction to cow's milk with associated histological changes and depression of alkaline phosphatase levels in the jejunal mucosa. In all seven cases parallel changes in alkaline phosphatase levels were noted in the organ culture specimens of initial biopsy subjected to in vitro challenge. The seven control infants tolerated cow's milk and did not have histological changes. The alkaline phosphatase levels were moderately increased in the jejunal mucosa in five of the seven infants. The alkaline phosphatase levels in the organ culture specimens of initial biopsy were increased after in vitro challenge in all seven infants. This study suggests that organ culture methods may be useful in the in vitro diagnosis of CMPSE, and also obviate the need for in vivo oral milk challenges and repeated biopsies.

Although cow's milk protein sensitive enteropathy (CMPSE) is a common cause of persistent diarrhoea, malabsorption, and failure to thrive in infancy, ${ }^{2}$ there is as yet no satisfactory or generally accepted way of diagnosing it. The clinical criteria of Goldman et al. $^{3}$ and Powell ${ }^{4}$ and the clinical and histological approaches of Shiner et al. ${ }^{5}$ and Iyngkaran et al. ${ }^{6}$ have their advantages and disadvantages. Recently organ culture methods have been successfully used in studying the effect of gluten on the small bowel mucosa of patients with coeliac disease. ${ }^{7}$ This study was undertaken to determine the usefulness of organ culture technique in establishing the diagnosis of CMPSE.

\section{Methods}

PATIENTS

Fourteen infants with diarrhoea, clinically suspected to be caused by intolerance to cow's milk protein,

-Address for reprint requests: N Iyngkaran, Department of Paediatrics Faculty of Medicine, University of Malaya, Kuala Lumpur, Malaysia.

Received for publication February 1980. who were admitted to the Department of Paediatrics between November 1978 to February 1979 were studied. Treatment initially involved elimination of cow's milk and substitution of a formula free of cow's milk (Sobee, Nutramigen, Pregestimil, or breast milk). When a satisfactory response was obtained, assessed clinically by lack of symptoms and satisfactory weight gain, the infants were discharged and the parents instructed not to introduce any new food item without our knowledge. About six to eight weeks later the infants were readmitted for milk challenge studies.

LOW-LACTOSE COW'S MILK

PROVOCATION TEST

Lactolac V (Co-operatieve Condensfabriek Friesland, Holland) was used for the challenge. If no reaction occurred after an initial feeding of $5 \mathrm{ml}$, the volume was doubled hourly for the first four hours and subsequently three hourly until the daily fluid requirement was met. After challenge the infants were closely monitored for clinical symptoms. The biopsy specimens were taken with the Watson paediatric capsule at or just distal to the duodenojejunal 
junction under fluoroscopic control. Jejunal biopsies were routinely taken before and 24 hours after milk challenge. Examination of the stools and jejunal biopsy studies before and after milk provocation was carried out as described previously. ${ }^{2} 6$

The pre-challenge jejunal biopsy specimens were divided into four pieces: two were placed in organ culture medium, one piece was used for alkaline phosphatase assay, and one piece was fixed in $10 \%$ formaldehyde for histological studies. Twenty-four hours after milk challenge the post-challenge biopsy was obtained and analysed for alkaline phosphatase level and histological deterioration.

Histological appearances of the biopsies were graded as described previously. ${ }^{6}$

The patients were classified into two groups on the basis of histopathological changes in the gut mucosa and the development of clinical symptoms especially diarrhoea after milk challenge (Table 1). Seven infants had no mucosal abnormality or clinical symptoms. These patients, considered as controls in the present study, clinically tolerated oral feeds of cow's milk, required no further treatment, and continued to develop normally. The other seven infants were intolerant to cow's milk and the oral challenge caused severe mucosal deterioration.

\section{ORGAN CULTURE METHOD}

Organ culture was carried out as previously described by Falchuk et al. ${ }^{7}$ with some modifications. Biopsy specimens were transported to the laboratory at room temperature in RPMI 1640 medium supplemented with $10 \%$ complement-inactivated fetal calf serum (Wellcome Burroughs, England), insulin $1.0 \mu \mathrm{mol} / 1$ ( $0.5 \mathrm{mg} / 100 \mathrm{ml}$ medium $)$, crystalline peni-

Table 1 Clinical features of 14 infants with diarrhoea, seven with reaction and seven without reaction to cow's milk provocation

\begin{tabular}{|c|c|c|c|}
\hline & & $\begin{array}{l}\text { Group I } \\
\text { (Reactors) }\end{array}$ & $\begin{array}{l}\text { Group II } \\
\text { (Non-reactors) }\end{array}$ \\
\hline $\begin{array}{l}\text { No. of cases } \\
\text { Age at initial admission } \\
\quad \text { (days) } \\
\text { Sex ratio M:F } \\
\text { Artificial feeding } \\
\text { Mixed } \\
\text { Birth weight (kg) } \\
\\
\text { Age at onset of diarrhoea } \\
\text { (days) } \\
\text { Duration of diarrhoea } \\
\text { (days) } \\
\text { Weight at initial } \\
\text { admission (kg) } \\
\text { Age at readmission for } \\
\text { milk challenge (davs) } \\
\text { Weight at readmission for } \\
\text { milk challenge (kg) }\end{array}$ & $\begin{array}{l}\text { Mean } \\
\text { Range } \\
\text { Mean } \\
\text { Range } \\
\text { Mean } \\
\text { Range } \\
\text { Mean } \\
\text { Range } \\
\text { Mean } \\
\text { Range } \\
\text { Mean } \\
\text { Range }\end{array}$ & $\begin{array}{c}7 \\
46 \cdot 6 \pm 39 \cdot 8 \\
18-135 \\
4: 3 \\
5 \\
2 \\
3 \cdot 1 \pm 0 \cdot 5 \\
2 \cdot 5-4 \\
32 \pm 46 \cdot 6 \\
5-135 \\
16 \cdot 6 \pm 12 \cdot 2 \\
2-30 \\
3 \cdot 7 \pm 2 \cdot 1 \\
2 \cdot 35-8 \cdot 1 \\
168 \pm 122 \\
60-420 \\
6 \cdot 5 \pm 1 \cdot 8 \\
4 \cdot 9-9 \cdot 5\end{array}$ & $\begin{array}{c}7 \\
110 \pm 76 \\
30-255 \\
3: 4 \\
4 \\
3 \\
2 \cdot 9 \pm 0 \cdot 5 \\
1 \cdot 9-3 \cdot 4 \\
98 \pm 84 \\
14-253 \\
12 \cdot 4 \pm 21 \\
3-60 \\
4 \cdot 5 \pm 1 \cdot 5 \\
1 \cdot 94-6 \cdot 3 \\
171 \pm 74 \\
90-297 \\
6 \cdot 1 \pm 1 \cdot 4 \\
3 \cdot 7-8 \cdot 0\end{array}$ \\
\hline
\end{tabular}

cillin $0 \cdot 17 \mathrm{mmol} / 1(6 \cdot 2 \mathrm{~g} / 100 \mathrm{ml})$, streptomycin 0.2 $\mathrm{mmol} / 1(13.5 \mathrm{mg} / 100 \mathrm{ml})$, glutamine $2 \mathrm{mmol} / \mathrm{l}(30$ $\mathrm{mg} / 100 \mathrm{ml})$, and glucose $1.25 \mathrm{mmol} / 1(366 \mathrm{mg} / 100$ $\mathrm{ml})$. The medium was sterilised by Millipore filtration through $0.22 \mu \mathrm{m}$ filter and treated before use with $95 \% \mathrm{O}_{2}$ and $5 \% \mathrm{CO}_{2}$ gas mixture.

The two pieces of pre-challenge biopsy specimen for organ culture were trimmed to about $3 \times 3 \mathrm{~mm}$ each. The two specimens were placed villous side up single onto separate stainless-steel wire mesh grids (Falcon 3014, 60 mesh) and each grid was then suspended over the central well of a plastic culture dish (No. 3037, Falcon Plastics, Los Angeles, California). To the central well of one culture dish was added about $1 \mathrm{ml}$ of culture medium and to the central well of the second culture dish $1 \mathrm{ml}$ of RPMI 1640 supplemented with cow's milk. In both cases the volume of the respective fluid medium added was such that the grid was lifted off its rest by surface tension. This practice considerably enhanced the viability and growth of the tissue. Parallel in vitro studies in presence of only RPMI 1640 medium or RPMI 1640 supplemented with cow's milk, in the central well of the culture dishes was performed in all cases. To the outside ring well of both culture dishes was added $2 \mathrm{ml}$ of medium or Hanks balanced solution to maintain humid conditions. The dishes were then placed in closed Plexiglass containers, treated with a $95 \%$ oxygen and $5 \%$ carbon dioxide gas mixture and incubated for 24 hours at $37^{\circ} \mathrm{C}$. At the end of the overnight incubation period the tissues were removed from the culture and immediately wrapped in aluminium foil and placed at $-70^{\circ} \mathrm{C}$ for subsequent protein and alkaline phosphatase estimations.

Cow's milk which formed the in vitro challenge to the tissue, was added to the medium at a concentration of $0.14 \mathrm{mg} / \mathrm{ml}$. A standard stock solution of cow's milk protein which was used in all the tests was prepared as follows: $6 \mathrm{~g}$ milk (full cream milk) was thoroughly mixed in RPMI 1640 in a mortar, then centrifuged at $15000 \mathrm{~g}$ for 30 minutes in a Sorvall centrifuge. The supernatant was passed through a $\mathbf{0 . 2 2} \mu \mathrm{m}$ Millipore filter and stored sterile at $4^{\circ} \mathrm{C}$.

\section{ENZYME ASSAY}

Specimens were homogenised thoroughly in $0.3 \mathrm{ml}$ of cold distilled water. The homogenate was centrifuged and the supernatant assayed for alkaline phosphatase according to the method of Garen and Levinthal ${ }^{8}$ and for protein according to the method of Lowry et al. ${ }^{9}$ Alkaline phosphatase activity was expressed in units representing micromoles of para-nitrophenol phosphate hydrolysed per minute per gram of tissue protein. 


\section{Results}

Fourteen infants were studied. The clinical features of the infants were similar to those of infants studied previously ${ }^{26}$ and are summarised in Table 1.

At the time of readmission for milk challenge studies all 14 infants were clinically well and registered satisfactory weight gains. The stools were negative for enteric pathogens. Histological appearances of the pre-challenge jejunal biopsies were normal in 10 and mildly abnormal in four infants.

After milk provocation seven infants developed clinical symptoms of diarrhoea (with or without vomiting, fever, and lethargy) with histological changes, and depression of alkaline phosphatase levels in the post-challenge jejunal mucosa. In the organ culture specimens after in vitro milk challenge similar depression of alkaline phosphatase levels was noted in all seven infants.

Seven infants clinically tolerated cow's milk. No significant histological alteration was noted in the post-challenge jejunal mucosa. The levels of alkaline phosphatase in the post-challenge biopsy specimens were considerably higher than in the pre-challenge in five of the seven infants. In the organ culture specimens from all these seven infants a consistent and moderate increase in the alkaline phosphatase levels were observed after in vitro challenge.

The results of the histological and enzymological studies are summarised in Table 2.

\section{Discussion}

Cow's milk protein sensitive enteropathy has been a diagnostic enigma for clinicians involved in the management of diarrhoeal disease in young infants. Moreover, all current methods for the diagnosis of CMPSE are based on in vivo milk provocation, which can be hazardous and life threatening. ${ }^{34}$ As many of the infants with persistent diarrhoea are ill at the time of admission diagnostic milk challenge studies often have to be delayed until the infants can withstand the consequences of any adverse reaction to milk provocation. This may pose difficulties in planning a rational approach to the management of these infants.

In the present study seven infants with positive milk challenge had CMPSE by the criteria of Iyngkaran et $a .^{6}$ and the other seven infants who did not react to cow's milk can be considered as controls. In both these groups of infants there is a good correlation between the clinical, histological, and

Table 2 Histological and enzymological results of jejunal biopsy and organ culture studies in 14 infants before and after cow's milk provocation

\begin{tabular}{|c|c|c|c|c|c|c|c|c|c|c|c|c|}
\hline \multirow[t]{2}{*}{ Case } & & \multirow{2}{*}{$\begin{array}{l}\text { Symptoms } \\
\text { onset }(h)\end{array}$} & \multicolumn{7}{|c|}{ Jejunal biopsy" } & \multirow{2}{*}{\multicolumn{3}{|c|}{$\frac{\text { Organ culture } \dagger}{\text { Alkaline phosphatase }}$}} \\
\hline & & & \multicolumn{4}{|c|}{ Histology $\ddagger$} & \multicolumn{3}{|c|}{ Alkaline phosphatases $\S$} & & & \\
\hline $\begin{array}{l}\text { Reactor } \\
\text { group }\end{array}$ & $\begin{array}{l}1 \\
2 \\
3 \\
4 \\
5 \\
6 \\
7 \\
\text { Mean } \\
\pm \text { SD }\end{array}$ & $\begin{array}{c}14 \\
5 \\
9 \\
8 \frac{1}{8} \\
10 \\
10 \\
9\end{array}$ & $\begin{array}{l}\mathbf{N} \\
\mathbf{N} \\
\mathbf{N} \\
\mathbf{N} \\
\mathbf{N} \\
\mathbf{N} \\
\mathbf{N}\end{array}$ & $\begin{array}{c}0 \\
0 \\
3 \\
0 \\
0 \\
3 \\
1 \\
1 \\
\pm 1 \cdot 4\end{array}$ & $\begin{array}{l}\text { Mod VA } \\
\text { MVA } \\
\text { SVA } \\
\text { Mod VA } \\
\text { MVA } \\
\text { Mod VA } \\
\text { Mod VA }\end{array}$ & $\begin{array}{c}9 \\
7 \\
12 \\
8 \\
5 \cdot 5 \\
11 \\
9 \\
8 \cdot 8 \\
\pm 2 \cdot 2\end{array}$ & $\begin{array}{c}89 \\
423 \\
456 \cdot 1 \\
88 \cdot 6 \\
233 \cdot 3 \\
155 \\
191 \cdot 4 \\
233 \cdot 8 \\
+150 \cdot 2\end{array}$ & $\begin{array}{r}34 \cdot 4 \\
121 \cdot 7 \\
120 \cdot 7 \\
44 \cdot 7 \\
118 \cdot 5 \\
115 \cdot 7 \\
119 \cdot 4 \\
96 \cdot 4 \\
\pm 39\end{array}$ & $\begin{array}{l}-61 \cdot 3 \\
-71 \cdot 2 \\
-73 \cdot 5 \\
-49 \cdot 5 \\
-49 \cdot 2 \\
-25 \cdot 4 \\
-37 \cdot 6 \\
-52 \cdot 5 \\
\pm 17 \cdot 5\end{array}$ & $\begin{array}{l}155 \\
421 \cdot 3 \\
178 \cdot 3 \\
156 \cdot 2 \\
106 \cdot 4 \\
242 \\
283 \cdot 5 \\
220 \cdot 4 \\
+106 \cdot 4\end{array}$ & $\begin{array}{r}70.4 \\
37 \cdot 4 \\
142.6 \\
80.9 \\
54 \\
207.4 \\
93 \cdot 8 \\
98 \cdot 1 \\
+58.7\end{array}$ & $\begin{array}{l}-54 \cdot 6 \\
-91 \cdot 1 \\
-20 \\
-48 \cdot 2 \\
-49 \cdot 2 \\
-14 \cdot 3 \\
-66.9 \\
-49 \cdot 2 \\
\pm 26 \cdot 4\end{array}$ \\
\hline $\begin{array}{l}\text { Control } \\
\text { group }\end{array}$ & $\begin{array}{l}1 \\
2 \\
3 \\
4 \\
5 \\
6 \\
7 \\
\text { Mean } \\
\pm \text { SD }\end{array}$ & $\begin{array}{l}\text { Nil } \\
\text { Nil } \\
\text { Nil } \\
\text { Nil } \\
\text { Nil } \\
\text { Nil } \\
\text { Nil }\end{array}$ & $\begin{array}{l}\mathbf{N} \\
\text { Mild } \\
\mathbf{N} \\
\text { Mild } \\
\mathbf{N} \\
\text { Mild } \\
\mathbf{N}\end{array}$ & $\begin{array}{c}0 \\
6 \\
3 \\
4 \\
0 \\
5 \\
0 \\
2 \cdot 6 \\
\pm 2 \cdot 6\end{array}$ & $\begin{array}{l}\mathbf{N} \\
\text { Mild } \\
\mathbf{N} \\
\text { Mild } \\
\mathbf{N} \\
\text { Mild } \\
\mathbf{N}\end{array}$ & $\begin{aligned} 0 \\
7 \\
3 \\
4 \\
0 \\
6 \\
0 \\
2 \cdot 9 \\
+2 \cdot 9\end{aligned}$ & $\begin{array}{c}62.6 \\
77.9 \\
159 \\
113 \\
159 \cdot 5 \\
185 \cdot 2 \\
220.9 \\
139.7 \\
+57.6\end{array}$ & $\begin{array}{r}54 \cdot 6 \\
102.4 \\
228 \cdot 7 \\
131 \cdot 3 \\
189.0 \\
185.2 \\
228.0 \\
159.9 \\
+\quad 65.9\end{array}$ & $\begin{array}{c}-12 \cdot 8 \\
+31 \cdot 5 \\
+43 \cdot 8 \\
+16 \cdot 2 \\
+18 \cdot 5 \\
0 \\
+3 \cdot 2 \\
+14 \cdot 3 \\
+19.4\end{array}$ & $\begin{array}{c}337 \cdot 8 \\
130 \cdot 9 \\
251 \cdot 2 \\
362 \\
170 \cdot \\
192 \cdot 7 \\
229 \cdot 0 \\
239 \cdot 1 \\
+85.4\end{array}$ & $\begin{array}{l}411 \cdot 8 \\
164 \cdot 9 \\
283 \cdot 5 \\
513 \cdot 4 \\
216 \\
250 \\
282 \cdot 3 \\
303 \cdot 1 \\
\pm 120\end{array}$ & $\begin{array}{l}+21.9 \\
+26 \\
+12.9 \\
+41.8 \\
+27 \\
+30.2 \\
+23.3 \\
+26.2 \\
\pm \quad .8\end{array}$ \\
\hline
\end{tabular}

*Two biopsies obtained, one before in vivo milk challenge (Pre) and a second one 24 hours after initial fee (Post).

†Initial biopsy cultured in RPMI 1640 only (Pre) or RPMI 1640 supplemented with milk (Post).

$\ddagger$ Histological grading: normal $(N)=0-3$. Mild villous atrophy $($ MVA $)=4-7$. Moderate villous atrophy $($ Mod VA) $=8-11$. Severe villous atrophy (SVA) $=>11$

$\S$ Percentage change $=\frac{\text { Pre-challenge }}{\text { Post-challenge }} \times 100$

- decrease

+ increase

Alkaline phosphatase unit $=\mu \mathrm{mol}$ P-nitrophenol phosphate hydrolysed $\mathrm{per} \mathrm{min} / \mathrm{g}$ tissue protein. 
enzymological responses to the in vivo milk challenge. Moreover, the changes in alkaline phosphatase levels in pre-challenge biopsy specimens after in vitro challenge in organ culture parallel those of fresh jejunal mucosa specimens obtained before and after in vivo challenge. These observations suggest that in vitro challenge tests of a single biopsy specimen provide results which remove the need for in vivo challenge and the taking of a post-challenge biopsy.

In the control group of infants the post-challenge alkaline phosphatase levels were higher than the prechallenge values in both the fresh jejunal biopsy and organ culture specimens. We have no satisfactory explanation for this observation. However, because the pre- and post-milk challenge biopsy specimens are different in the case of in vivo challenge but concern the same tissue (initial biopsy) in the case of the cultured tissue challenged in vitro, it appears likely that the enhanced alkaline phosphatase is promoted by the milk. It is possible that the raised alkaline phosphatase reflects an enhanced epithelial cell turnover rate induced by the milk protein.

The present study suggests that organ culture technique may be useful in studying the effects of cow's milk protein on the small bowel mucosa. It would appear that this technique has the potential for obviating the present need for in vivo oral milk challenges, and serial biopsies in the diagnosis of CMPSE. Moreover, the present study also suggests that changes in alkaline phosphatase levels may provide an additional sensitive parameter for diagnosis of CMPSE besides changes in histological appearances of the jejunal mucosa. Additional studies are needed to confirm the present observations.
We are most grateful to $\mathbf{P}$ Thirukumar, T Peter, and R Gunaselan for technical assistance and to Sister Tang, Azizah, and the nursing staff for their enthusiastic co-operation. This project was funded by the University of Malaya Research Grants Committee.

\section{References}

${ }^{1}$ Kuitunen P, Visakorpi JK, Savilahti E, Pelkonen P. Malabsorption syndrome with cow's milk intolerance. Arch Dis Child 1975; 50: 351-6.

${ }^{2}$ Iyngkaran N, Robinson MJ, Davis KA et al. Protracted diarrhoea in infancy: cow's milk protein sensitive enteropathy an important cause. Aust J Paediatr 1979; 15: 266-70.

${ }^{3}$ Goldman AS, Anderson DW, Sellers WA, Saperstein S, Kniker WT, Halpern SR. Milk allergy I. Oral challenge with milk and isolated milk proteins in allergic children. Pediatrics 1963; 32: 425-43.

4Powell GK. Milk and soy-induced enterocolitis of infancy. $J$ Pediatr 1978; 93: 553-60.

${ }^{5}$ Shiner M, Ballard J, Brook CGD, Herman S. Intestinal biopsy in the diagnosis of cow's milk protein intolerance without acute symptoms. Lancet 1975; 2: 1060-3.

'Iyngkaran N, Robinson MJ, Prathap K, Sumithran E, Yadav M. Cow's milk protein-sensitive enteropathy: combined clinical and histological criteria for diagnosis. Arch Dis Child 1978; 53: 20-6.

${ }^{7}$ Falchuk ZM, Gebhard RL, Sessoms C, Strober W. An in vitro model of gluten sensitive enteropathy. $J$ Clin Invest $1974 ;$ 53: 487-500.

${ }^{8}$ Garen, Levinthal C. A fine-structure genetic and chemical study of the enzyme alkaline phosphatase of E. coli I. Purification and characterisation of alkaline phosphatase. Biochim Biophys Acta 1960; 38: 470-83.

${ }^{9}$ Lowry $\mathrm{OH}$, Rosebrough NJ, Farr AL, Randall RJ. Protein measurement with the Folin phenol reagent. $J$ Biol Chem 1951; 193: 265-75. 